\title{
THE INTERACTION OF OXIDATION PRODUCTS OF PYROGALLOL WITH POLY-L-LYSINE. A MODEL OXIDATIVE BEER HAZE
}

\author{
by
}

\author{
HENRY I. ABRASH \\ Department of Chemistry, Carlsberg Laboratory \\ Gamle Carlsbergvej 10 - DK-2500 Copenhagen, Valby ${ }^{1}$ \\ 1) Current address: Department of Chemistry, California State University at Northridge \\ Northridge, California 91324 , USA
}

Key words: beer haze, lysozyme, oxidation, poly-L-lysine, PVP, pyrogallol

Iodate oxidation of pyrogallol at $\mathrm{pH} 4$ produces an agent capable of precipitation poly-L-lysine and lysozyme. This substance is neither purpurogallin nor one of its oxidation products. The solubility of the poly-t-lysine precipitate in $6 \mathrm{M}$-guanidine hydrochloride and in $1 \mathrm{M}-\mathrm{NaOH}$ indicates that hydrogen bonding is responsible for precipitation. While the oxidized pyrogallol solutions do not contain tannins detectable by the method of CHAPON, polyvinylpyrollidone (PVP) does prevent precipitation. Once formed, the precipitate does not redissolve in PVP. The pyrogallol oxidation products have no effect on the lysine-free polypeptide poly-N(5) hydroxyethyl-L-glutamine.

\section{INTRODUCTION}

Model systems for the formation of beer haze by oxidation have been extensively studied by CHAPON and coworkers who demonstrated that peroxidase catalyzed oxidation of beer rapidly produces haze (2) and that similar hazes can be ormed by peroxidase catalyzed oxidation of polyphenols such as quercitin or catechin in the presence of acid-stable proteins such as ovalbumin or $\beta$-lactoglobulin (4). Changes in chromatographic behavior and haze activity due to peroxidase catalyzed oxidation of beer and of solutions of catechin or a synthetic procyanidin (1) indicate that oxidation leads to polymerization of the polyphenols, a moderate degree of polymerization producing tannins capable of forming precipitates with proteins in beer while further polymerization decreases haze activity. Studies with PVP' (3) suggest that the tannin-protein reaction is reversible and that precipitation occurs when the protein forms a complex with a sufficient number of tannin molecules. The oxidative polymerization of monomeric polyphenols such as catechin to form tannins appears to involve condensations of $o$-quinones derived from the polyphenol (7).

Another possibility is that the quinones formed by polyphenol oxidation might condense with protein side chains such as the $\varepsilon$-amino groups of lysine. Such reactions occur rapidly in neutral solutions when catechol is oxidized by $o$-diphenol oxidase in the presence 
of amino acids $(8,9,11)$ and proteins $(8,12)$. The rates of irreversible condensation between $o$-quinones and $\varepsilon$-amino groups at the acid $\mathrm{pH}$ values (about 4) characteristic of beer should be considerably slower than the reaction at neutrality because of protonation of the amino groups in acidic solutions. To test whether such reactions might still be fast enough to compete with polyphenol polymerization and to assess the possible significance of $o$-quinone-amine condensations in beer haze formation, we have investigated the behavior of poly-L-lysine in a system in which pyrogallol is oxidized. While probably not an important agent in the formation of natural beer hazes, pyrogallol offers a much simpler model system for quinone reactions than such natural polyphenolic haze precursors as catechin. Preliminary studies were also performed with lysozyme - a protein rich in basic amino acids - and the lysine-free polypeptide PHEG.

\section{MATERIALS AND METHODS}

\subsection{Materials}

Analytic grade pyrogallol (E. Merck, Darmstadt, Germany) was sublimed in vacuo and stored in the dark in a tightly closed container. The absence of color in freshly prepared solutions showed that there was no oxidation of the crystals during storage or manipulation. Purpurogallin, prepared according to the methods of EVANS and DENN (5) and sublimed in vacuo, was bright orange and melted at $184-185^{\circ} \mathrm{C}\left(10^{\circ} \mathrm{C} / \mathrm{min}\right.$ heating rate $)$. Aqueous solutions of purpurogallin were prepared by diluting $0.300 \mathrm{mg} / \mathrm{ml}$ methanolic stock solutions. Poly-L-lysine (mol.wt.41,000) and lysozyme ( $3 x$ recrystallized) were from Sigma (St. Louis, Mo.). Concentrations of stock solutions of these two reagents were determined by amino acid analysis (section 2.3). The Luviskol K90 preparation of PVP (mol.wt. 700,000) was a gift from J. A. SøRENSEN. Poly-N(5)hydroxyethyl-L-glutamine (PHEG-4) was a gift from Dr. NERI, Sclavo Co., Siena, Italy. Guanidine hydrochloride (puriss.) was from Fluka AB, Switzerland, and potassium iodate was from
Struers, Copenhagen. All other reagents were analytic grade from E. Merck, Darmstadt.

\subsection{Spectra}

Ultraviolet-visible spectra of oxidizing systems were recorded from $225-700 \mathrm{~nm}$ using a Pye-Unicam, SP 800 ultraviolet spectrophotometer (Cambridge, England). The reference cell contained the same acetate buffer used in the oxidation reaction.

\subsection{Amino acid analysis}

Amino acid analyses of haze precipitates, supernatant solutions and stock solutions of poly-L-lysine and lysozyme were performed after 24 hours hydrolysis with $6 \mathrm{M}-\mathrm{HCl}$ at $110^{\circ} \mathrm{C}$ in sealed ampoules. Hydrolysates were analyzed either with a Beckman Spinco amino acid analyzer (Palo Alto, Calif.) with a $12 \mathrm{~cm}$ Aminex column using $\mathrm{pH} 5.28$ citrate buffer or with a Durrum Model D 500 amino acid analyzer (Palo Alto, Calif.) using the standard procedure in the Durrum Manual. The same ninhydrin development method was used in both procedures. The mass of poly-L-lysine was estimated by multiplying the moles of lysine found by the mass of a lysine residue (128).

\subsection{Thin layer chromatography}

Thin layer chromatography of oxidation was attempted using silica gel $60 \mathrm{~F}_{254}$ on $0.25 \mathrm{~mm}$ plastic sheets (E. Merck, Darmstadt) or polyamide on plastic (BDH Chemicals, Ltd., Poole, England) as the stationary phase. The polyamide sheets were soaked in a $250 \mathrm{mg} / \mathrm{l}$ solution of 2-(tert-butylphenyl)-5-(4-biphenylyl)1,3,4-oxadiazol (Fluka, Switzerland) and dried before use, and the chromatograms were analyzed by means of a Mineralight UVS-11 lamp (Ultraviolet Products, San Gabriel, Calif.). Moving phases were: 1) water-ethanol-ethyl acetate $(4: 2: 1 \mathrm{v} / \mathrm{v}) ; 2)$ water-methanol $(1: 1) ; 3)$ $10 \%$ acetic acid in chloroform $(\mathrm{v} / \mathrm{v})$.

\subsection{The model haze system}

To $3.0 \mathrm{ml}$ of an acetate buffer $(I=0.10, \mathrm{pH}$ 3.98 to 4.09 depending on the experiment) maintained at $25^{\circ} \mathrm{C}$ in a $1.0 \mathrm{~cm}$ silica cuvette, 
were added $50 \mu 1$ of the appropriate freshly prepared pyrogallol stock solution and $250 \mu \mathrm{l}$ of poly-L-lysine stock solution. In some experiments, the poly-L-lysine was dissolved directly in the buffer. Addition of potassium iodate solution, varying in concentration from 0.047 to $0.062 \mathrm{M}$ and in volume from 10 to 130 $\mu \mathrm{l}$, initiated the oxidation. Spectra were recorded from 450 to $225 \mathrm{~nm}$, initially at two minute intervals, then less frequently as the reaction rate decreased. After 30 minutes, the spectrum was periodically scanned from 700 to $315 \mathrm{~nm}$. In several experiments, the haze was centrifuged after two or three hours for twenty minutes at 2,000 rev./min, the precipitate washed once with one $\mathrm{ml}$ water and recentrifuged. Amino acid analyses were performed on a suspension of the precipitate in one $\mathrm{ml}$ water, on the poly-L-lysine stock solution and, in some cases, the untreated supernate.

The lysozyme haze was formed by a reaction between $3.0 \mathrm{ml}$ of $1 \mathrm{mg} / \mathrm{ml}$ lysozyme in $\mathrm{pH} 4.09$ acetate buffer, $50 \mu \mathrm{l} 0.090 \mathrm{M}$-pyrogallol and 130 $\mu l 0.055 \mathrm{M}$-pyrogallol and $130 \mu \mathrm{l} 0.055 \mathrm{M}-\mathrm{KIO}_{3}$. The intermediate spectra were not recorded, but the precipitate was recovered and analyzed in the same way as the poly-L-lysine precipitate.

Variations in the experimental procedure involving control experiments, the investigation of the influence of time of addition of poly-L-lysine, the effects of PVP, PHEG and purpurogallin, and variations in the $\mathrm{KIO}_{3}$ pyrogallol ratio are described in section 3 .

\subsection{Stoichiometry of oxidation}

A $0.0100 \mathrm{M}$-solution of sodium thiosulfate pentahydrate was standardized by mixing $1.0 \mathrm{ml}$ of $0.00188 \mathrm{M}$-potassium iodate in $\mathrm{pH} 4.09$ acetate buffer, $0.10 \mathrm{ml} \mathrm{M}-\mathrm{HCl}$ and $1.0 \mathrm{ml} 0.033$ $\mathrm{M}$-sodium iodide and titrating with the thiosulfate to a starch end point. To determine the stoichiometry of the iodate-pyrogallol reaction, $1.0 \mathrm{ml} 0.0353 \mathrm{M}$-pyrogallol and $1.0 \mathrm{ml}$ $0.0470 \mathrm{M}-\mathrm{KIO}_{3}$ were added to $23.0 \mathrm{ml} 0.10$ $\mathrm{M}$-acetate buffer, $\mathrm{pH} 4.09$. Aliquots $(1.0 \mathrm{ml})$ were removed at various times, mixed with 0.10 $\mathrm{ml} 1 \mathrm{M}-\mathrm{HCl}$ and $20 \mu \mathrm{l} 1 \%$ starch and titrated with thiosulfate. Iodate consumption ceased after one hour.

\section{MOLECULAR STRUCTURES}
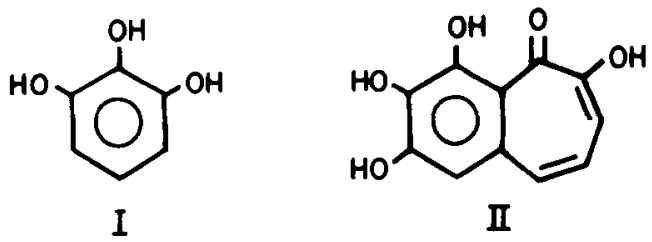

\section{RESULTS}

\subsection{Spectroscopic changes during oxidation}

During the first ten minutes of oxidation of $0.21 \mathrm{~mm}$-pyrogallol (I) by $0.74 \mathrm{mM}$-potassium iodate at $\mathrm{pH} 3.98$, weak extinction bands appear at 275, 305 and $400 \mathrm{~nm}$ while strong extinction develops below $235 \mathrm{~nm}$ (Fig. 1a). The 275 and $305 \mathrm{~nm}$ maxima, which are due to purpurogallin (II), disappear during the next hour, and there is also a decrease in extinction at $400 \mathrm{~nm}$ and a further increase in extinction at low wavelengths and in the $325-370 \mathrm{~nm}$ range. There are no spectroscopic changes after 90 minutes.

When the pyrogallol-iodate ratio is approximately $2: 1 \quad(0.32 \mathrm{mM}$-pyrogallol, 0.15 $\mathrm{mM}-\mathrm{KIO}_{3}$ ), the stoichiometric ratio for the oxidation of pyrogallol to purpurogallin, the 275 and $305 \mathrm{~nm}$ peaks do not decay, and a third weak purpurogallin shoulder at $375 \mathrm{~nm}$ is apparent. Although the extinction at $400 \mathrm{~nm}$ is stronger than for pure purpurogallin (Fig. 1b), the maximum at $400 \mathrm{~nm}$ is not present. The presence of strong extinction at low wavelength shows that purpurogallin is not the sole oxidation product. Based on an estimated extinction coefficient for purpurogallin at $305 \mathrm{~nm}$ in $\mathrm{pH}$ 4.09 acetate buffer of $2.1 \times 10^{4}$ liter $\cdot \mathrm{mole}^{-1}$ $\mathrm{cm}^{-1}$, the estimated yield of purpurogallin is at most $20 \%$.

An experiment in which $0.060 \mathrm{~mm}$ purpurogallin was oxidized in $0.14 \mathrm{mMKIO}_{3}$ (Fig. 1b) shows that the decay of the 275 and $305 \mathrm{~nm}$ extinction maxima in the presence of excess $\mathrm{KIO}_{3}$ is due to further oxidation of purpurogallin. There is a decrease in extinction between 265 and $335 \mathrm{~nm}$ and slight increases below $240 \mathrm{~nm}$ and above $335 \mathrm{~nm}$. These increases are not sufficient to explain the strong extinction below $235 \mathrm{~nm}$ or the transient extinc- 
tion at $400 \mathrm{~nm}$ when pyrogallol is oxidized in excess $\mathrm{KIO}_{3}$.

\subsection{Stoichiometry of oxidation}

When $1.41 \mathrm{~mm}$-pyrogallol is oxidized in the

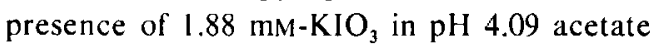
buffer, 0.76 mole iodate is consumed for every mole pyrogallol. This is considerably larger than the 0.50 ratio required for purpurogallin formation.

\subsection{Thin layer chromatography}

None of the combinations of stationary and moving phases used adequately resolves the oxidation product mixture. In all cases, solutions that had been oxidized for at least one hour contained only material with low $\mathbf{R}_{\mathrm{F}}$ values. The greatest movement was observed with $10 \%$ acetic acid in chloroform on silica gel which gave a continuous streak from $R_{F} 0$ to 0.32 . All the material detectable by use of the fluorescent indicator was also yellow-brown.

\subsection{Haze information}

Poly-L-lysine concentrations ranging from 6 to $600 \mu \mathrm{g} / \mathrm{ml}$ have no influence on the spectra of solutions in which iodate oxidizes pyrogallol at $\mathrm{pH}$ 4. However, turbidity is apparent, both visually and by increased apparent extinction above $500 \mathrm{~nm}$ due to light scattering, after about one hour. The dark red-brown precipitate responsible for the turbidity can be centrifuged easily and coagulates over 24 hours. This precipitate is insoluble in $1 \mathrm{M}-\mathrm{HCl}$. methanol and carbon tetrachloride but dissolves readily in either $1 \mathrm{M}-\mathrm{NaOH}$ or in 6 M-guanidine hydrochloride. The $\mathrm{NaOH}$ solution of the precipitate has strong extinction below $235 \mathrm{~nm}$ but no maxima at higher wavelengths. No turbidity or precipitate results from the action of either pyrogallol or $\mathrm{KIO}_{3}$ alone on poly-L-lysine.

Poly-L-lysine need not be present during the initial stages of oxidation to produce a precipitate. Precipitates were formed when 250 $\mu \mathrm{l}$ of $600 \mu \mathrm{g} / \mathrm{ml}$ poly-L-lysine was added to 3.0 $\mathrm{ml}$ of solutions in which $0.26 \mathrm{~mm}$-pyrogallol had been oxidized by $1.10 \mathrm{mM}-\mathrm{KIO}_{3}$ for as long as 21 hours. The relative amounts of polyphenolic material precipitated at the various times were
Spectroscopic Changes

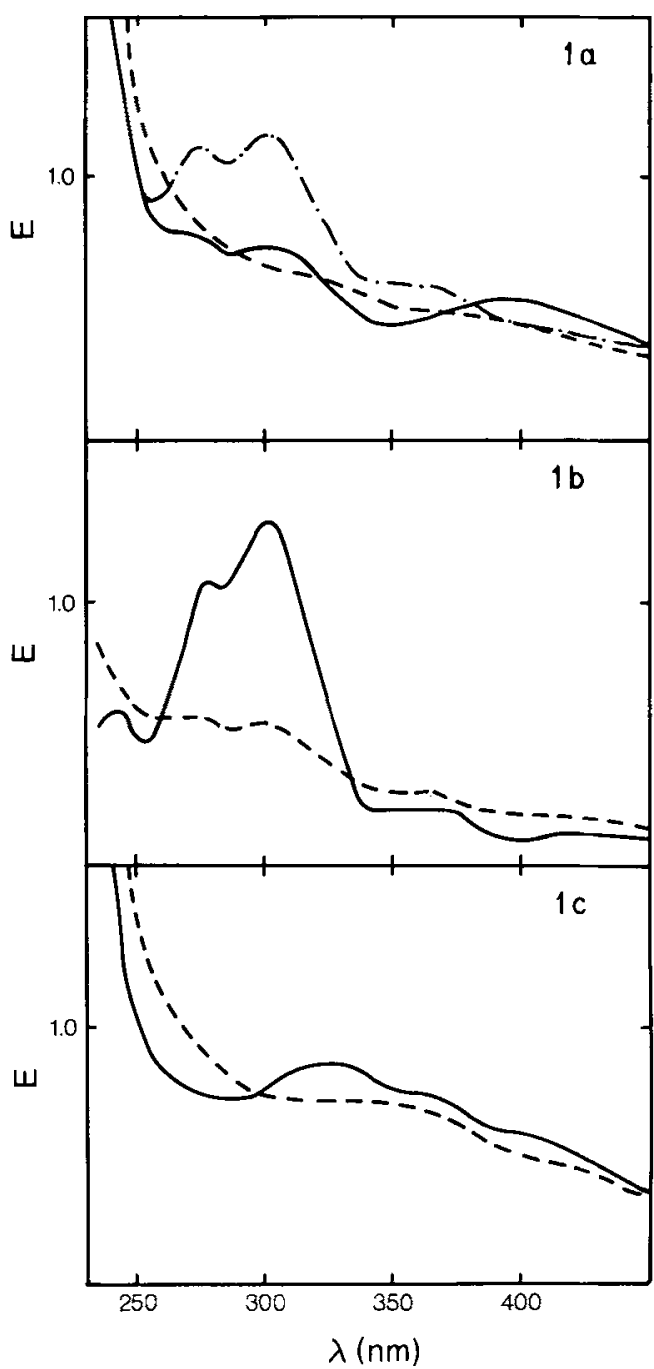

Figure 1. Spectroscopic changes during pyrogallol oxidation.

la. $0.21 \mathrm{~mm}$ pyrogallol oxidized by $0.74 \mathrm{mM}$ potassium iodate at $\mathrm{pH} 3.98$ for 12 minutes; ---oxidized for 160 minutes; --.---- $0.32 \mathrm{~mm}$-pyrogallol oxidized by $0.15 \mathrm{~mm}$-potassium iodate presence of 33 $\mu \mathrm{g} / \mathrm{ml}$ poly-L-lysine at $\mathrm{pH} 4.09$ for 120 minutes.

lb. - Spectrum of $0.060 \mathrm{~mm}$-purpurogallin in the presence of $33 \mu \mathrm{g} / \mathrm{ml}$ poly-L-lysine at $\mathrm{pH} 4.09 ;-$ after oxidation with $0.14 \mathrm{~mm}$-potassium iodate for 200 minutes.

Ic. — Spectrum of $0.20 \mathrm{~mm}$-pyrogallol oxidized by $0.68 \mathrm{mM}$-potassium iodate in the presence of 75 $\mu \mathrm{g} / \mathrm{ml} \mathrm{PVP}$ and $0.39 \mathrm{mg} / \mathrm{ml}$ poly-L-lysine at $\mathrm{pH} 4.01$ for 10 minutes; --- oxidized for 165 minutes. 
Table I

Yields of Haze Precipitate

\begin{tabular}{c|c|c|c}
\hline $\begin{array}{c}\text { pyrogallol } \\
\text { concentration } \\
(\mathrm{mM})\end{array}$ & $\begin{array}{c}\text { poly-L-lysine } \\
\text { concentration } \\
(\mu \mathrm{g} / \mathrm{ml})\end{array}$ & $\begin{array}{c}\mu \mathrm{g} \text { poly-L-lysine } \\
\text { precipitated per } \\
\text { ml solution }\end{array}$ & $\begin{array}{c}\text { poly-L-lysine } \\
\text { concentration } \\
\text { in supernate }(\mu \mathrm{g} / \mathrm{ml})\end{array}$ \\
\hline 0.20 & 600 & 2.0 & -- \\
0.21 & 60 & 1.1 & --- \\
0.18 & 6 & 0.9 & -- \\
1.35 & 37 & approx. 10 & 10 \\
1.20 & 410 & 19 & 357 \\
\hline
\end{tabular}

estimated by redissolving the precipitates in 1 $\mathrm{M}-\mathrm{NaOH}$ and measuring the extinction at 325 $\mathrm{nm}$. This experiment indicates that the amount of polyphenol precipitated is independent of the time of addition of the poly-L-lysine. Late addition of poly-L-lysine does produce a more flocculent precipitate and a less stable haze.

The data in Table I show that the amount of poly-L-lysine precipitated is limited by the amount of pyrogallol present. At a given pyrogallol concentration, the concentration of poly-L-lysine has very little influence on the amount of polypeptide precipitated. On the other hand, the amount of poly-L-lysine precipitated is roughly proportional to the pyrogallol concentration. Attempts to study the reaction with $9.7 \mathrm{mM}$-pyrogallol were foiled by the precipitation of a polyphenolic oxidation product, most probably purpurogallin.

The haze is not due to purpurogallin or its oxidation products. There was no apparent turbidity after an hour's contact between 32 $\mu \mathrm{g} / \mathrm{ml}$ poly-L-lysine and $0.060 \mathrm{mM}$-purpurogallin at $\mathrm{pH} 4.09$ nor did oxidation of this solution with $0.14 \mathrm{mM}-\mathrm{KIO}_{3}$ produce a precipitate.

\subsection{The effect of PVP}

The presence of PVP during the early stages of pyrogallol oxidation alters the spectrum of the solution (Fig. 1c) by producing persistent extinction in the $325-375 \mathrm{~nm}$ range. The effect is not due to the interaction of PVP with either pyrogallol or $\mathrm{KIO}_{3}$ alone. PVP has no effect on the spectrum if it is added after oxidation is complete. No turbidity or precipitate forms during the oxidation of pyrogallol in the presence of either 0.078 or $1.0 \mathrm{mg} / \mathrm{ml} \mathrm{PVP}$, nor could any tannins be detected in an oxidized solution of $1.15 \mathrm{mM}$-pyrogallol by the PVP method of CHAPON (3). In the tannin analysis, the PVP concentration was slowly increased to $0.068 \mathrm{mg} / \mathrm{ml}$ without producing detectable turbidity.

The presence of PVP in concentrations as low as $0.078 \mathrm{mg} / \mathrm{ml}$ prevents precipitation when $0.20 \mathrm{mM}$-pyrogallol is oxidized in the presence of $390 \mu \mathrm{g} / \mathrm{ml}$ poly-L-lysine, nor does precipitation occur when $1.20 \mathrm{mM}$-pyrogallol is oxidized in the presence of $29 \mu \mathrm{g} / \mathrm{ml}$ poly-L-lysine and $0.071 \mathrm{mg} / \mathrm{ml}$ PVP. Addition of PVP after completion of oxidation but before addition of polyL-lysine also prevents precipitation. However, $0.078 \mathrm{mg} / \mathrm{ml}$ PVP does not redissolve the precipitate once it forms.

\subsection{Lysozyme haze}

A thick haze forms after eight minutes oxidation of $1.4 \mathrm{~mm}$-pyrogallol by $2.2 \mathrm{mM}-\mathrm{KIO}_{3}$ in the presence of $1 \mathrm{mg} / \mathrm{ml}$ lysozyme at $\mathrm{pH} 4.09$. This red-brown precipitate coagulates more readily than the poly-L-lysine haze. Like the poly-Llysine haze, it dissolves readily in 6M-guanidine hydrochloride.

\subsection{The effect of PHEG}

There are no spectroscopic effects due to the presence of approx. $0.1 \mathrm{mg} / \mathrm{ml}$ PHEG when $0.21 \mathrm{~mm}$-pyrogallol is oxidized at $\mathrm{pH} 4.09$, nor does PHEG prevent precipitation in the presence of $37 \mu \mathrm{l} / \mathrm{ml}$ poly-L-lysine. PHEG $(0.1$ $\mathrm{mg} / \mathrm{ml}$ ) does not form a precipitate or turbidity with the oxidation products of pyrogallol, even at pyrogallol concentrations as high as $1.24 \mathrm{~mm}$. 


\section{DISCUSSION}

Oxidation of pyrogallol at $\mathrm{pH} 4$ produces, among other products, one or more substances capable of precipitating poly-L-lysine and lysozyme. This precipitating agent is not purpurogallin, which is formed in the oxidation reaction, or further oxidation products of purpurogallin. The lack of influence of poly-L-lysine on the rate of oxidation or the spectroscopic changes due to oxidation and the fact that the precipitating agent persists long after oxidation has ceased indicates that oxidation intermediates such as monomeric quinones or semiquinones are not involved in the precipitation. Based on the spectra of fully oxidized solutions and the precipitate redissolved in $\mathrm{NaOH}$, the precipitating agent seems to have strong extinction below $235 \mathrm{~nm}$ and a featureless spectrum at higher wave lengths. Polymeric oxidation products such as biphenyls (6) or triphenoquinones (10) might be the precipitating agents.

The formation of the precipitate seems to involve hydrogen bonding since the precipitate dissolves both in guanidine hydrochloride and in $1 \mathrm{M}-\mathrm{NaOH}$. The first reagent is effective in disrupting all types of hydrogen bonds while the second prevents hydrogen bond donor activity by phenols by deprotonating them. There was no indication in the amino acid analyses of formation of non-hydrolyzable covalent condensation products between the $\varepsilon$-amino groups of poly-L-lysine and the polyphenol oxidation product.

The oxidation product that precipitates poly-L-lysine and lysozyme is selective in its interactions since it does not cause turbidity or precipitation with PVP or PHEG, two polymers capable of extensive hydrogen bonding. As shown by its effect on the oxidation spectrum (Fig. 1c), PVP does interact with oxidation intermediate, and its ability to prevent poly-Llysine precipitation when added to a fully oxidized solution shows that it complexes with the precipitating agent. These interactions do not, however, precipitate PVP.

According to the criterion of CHAPON (3) the oxidized solution contains no detectable amount of tannins. One possible explanation of the selectivity of the precipitating agent and its apparent inability to act as a tannin is that it might contain carboxyl groups due to ring cleavage reactions (13). Such molecules could complex with PVP, but their negative charges would prevent precipitation of the complex. On the other hand, a negatively charged precipitating agent would neutralize the positive charges of poly-L-lysine and lysozyme and thus aid precipitation.

The precipitation of poly-L-lysine is not readily reversible since $P V P$, which is effective in preventing precipitation, does not redissolve the precipitate. This may be due to a relatively slow conformational change of an initially formed polyphenol-poly-L-lysine complex to produce an insoluble, tightly bound complex.

\section{ACKNOWLEDGEMENTS}

We thank ElLA MEILING for performing the Chapon analysis for the tannin content of the oxidized pyrogallol solution.

\section{REFERENCES}

1. Chapon, L., S. Chapon, R. Seyer \& C. Louis: Experiences modeles illustrant quelques aspects du mecanisme de formation du trouble au froid. Proc. Eur. Brewery Conv,, 15th Congress, Nice 1975, Elsevier, Amsterdam pp. 423-438 (1975)

2. Chapon, L., B. Chollot \& E. Urion: Oxydation peroxydasique des bières. Phénomenès fondamentaux. Proc. Eur. Brewery Conv., 8th Congress, Vienna 1961, Elsevier, Amsterdam pp. 319-333(1961)

3. Chapon, L., B. Chollot \& E. Urion: Étude physico-chimique des associations entre protéines vegetales et substances polyphenoliques. Bull.Soc.Chim. Biol. 43, 429-442 (1961)

4. Chollot, B., L. Chapon \& E. Urion: Précurseurs polyphénoliques et protéiques du trouble d'oxydation peroxydasique. Proc. Eur. Brewery Conv., 8th Congress, Vienna 1961, Elsevier, Amsterdam pp. 334-350 (1961)

5. Evans, T. W. \& W. M. DenN: Organic oxidations by iodic acid. J. Am. Chem. Soc. 52, 3647-3649 (1930)

6. Harries, C.: Úber die Autoxydation des Pyrogallols. Chem. Ber. 35, 2954-2959 (1902)

7. Hathway, D. E. \& J. W. T. Seakins: Autoxidation of catechin. Nature 176, 218 (1955) 
8. Mason, H. S.: Reactions between quinones and proteins. Nature 175, 771-772 (1955)

9. Mason, H. S. \& E. W. Peterson: Melanoproteins I. Reactions between enzyme-generated quinones and amino acids. Biochim. Biophys. Acta 111, 134-146(1965)

10. Nierenstein, M.: An oxidation product of pyrogallol. J. Chem. Soc. 107, 1217-1220 (1915)

11. Pierpoint, W. S.: $o$-Quinones formed in plant extracts. Their reactions with amino acids and peptides. Biochem. J. 112, 609-617 (1969)

12. Pierpoint, W. S.: $o$-Quinones formed in plant extracts. Their reactions with bovine serum albumin. Biochem. J. 112, 619-629 (1969)

13. Schulze, H. \& W. Flaig: Zur Kenntnis der Huminsäuren, IV. Mitteilung. Uber die Ringsprengnung mehrwertiger Phenole mit Sauerstoff in alkalischem Medium. Ann. 575, 231-241 (1952) 